\title{
Comparison of multiple modulation techniques for various topologies of multilevel converters for single phase AC motor drive
}

\author{
Laith M. Akram Alsaqal ${ }^{1}$, Ahmed M. T. Ibraheem Alnaib ${ }^{2}$, Omar Talal Mahmood ${ }^{3}$ \\ ${ }^{1,2}$ Departement of Electrical Power Eng. Technologies, Northern Technical University, Iraq \\ ${ }^{3}$ Departement of Electrical Technologies, Northern Technical University, Iraq
}

\section{Article Info}

Article history:

Received Aug 17, 2018

Revised Nov 19, 2018

Accepted Dec 11, 2018

Keywords:

Cascaded MCs

LSC

Multilevel Converters

$\mathrm{NPC}-\mathrm{MCs}$

PSC

THD

\begin{abstract}
There are various types of Multilevel Converters (MCs) in addition to various types of modulation techniques for these types of MCs; the challenges in selecting the best one of them with regard to the amount of the required of components, and its harmonics content. So, a comparison study among these types has been done in this paper. For comparison study, the simulation of seven level of two popular topologies of MCs: Neutral Point Clamped (NPC) converter, and Cascaded-MCs were carried out with Matlab/Simulink software program. These converters are used to drive a single phase capacitor start motor drive. Multicarrier modulation control techniques are used for controlling the MCs; these techniques involve two main type: Level Shifted Carrier (LSC), and Phase Shifted Carrier (PSC). The comparison is made with respect to the performance factors as, the amplitude of the Total Harmonic Distortion (THD), and the DC-bus utilization performance which measured by Root Mean Square of the output voltage Vrms at variable modulation indices and variable carrier frequency. Based on simulation results it's found, that the cascaded-MC with PSC modulation method gives best results, in addition to the Alternative Phase Opposition Disposition APOD-LSC modulation technique (with even number of modulation frequency) generate the output voltage with a lower harmonic content compared with the other techniques.
\end{abstract}

Copyright $(2019$ Institute of Advanced Engineering and Science. All rights reserved.

\section{Corresponding Author:}

Ahmed M. T. Ibraheem Alnaib,

Departement of Electrical Power Eng. Technologies,

Northern Technical University, Mosul, Iraq.

Email: ahmed_alnaib85@yahoo.com

\section{INTRODUCTION}

Multilevel converter is materialized as an appropriate alternate to numerous difficulties produced by the conventional converter particularly in medium and high power applications [1]. Multilevel power converter is a power electronic system that synthesizes a required high output voltage from numerous levels of DC voltages as inputs, a high output voltage is generate at the output without using a transformer or with a transformer with small transformation ratio. This methodology has several benefits as contrasted with the standard power conversion manner. It leads to decrease voltage stress on the load and to provide waveforms with a high power quality. For operating at higher voltages the power switches are connected in a series type linking which is an essential feature of MLI. Thus the switching losses will be reduced and the efficiency will increase [2]. As a result of all these benefits, it is suggested for numerous applications for example AC motor drives, uninterrupted power supplies, flexible AC transmission systems, static VAR compensators, active filters, electric and hybrid electric vehicles, in addition to it is proposed for renewable energy sources as solar photovoltaic (PV), wind turbine generation source, and fuel cell supply. Especially the cascaded converter type it preferred to operate with these souses because it required isolated DC supply $[1,3]$. 
There are mainly three types of MCs configurations used in industrial applications: Neutral Point Clamped (NPC), Cascaded H-bridges inverter, and Flying capacitors (FLC) type inverter. A huge amount of storage capacitor is required in FLC-MC type inverter, it's difficult to obtain the pre-charging capacitors, more difficult to package and those bulky capacitors are expensive. In addition, it has the problem of high voltage unbalance. NPC and cascaded-MC are usually used for motor drive and power quality improvement applications $[4,5]$. So in this paper these two later types was simulated in our work with seven level, the single phase capacitor start is employed as load for the simulated converters because this type of motors are the most usual in home application, and small industries.

\section{SEVEN LEVEL NEUTRAL POINT CLAMPED MULTILEVEL CONVERTER}

In NPC-MC, sharing a common DC source and it is subdivided by using capacitor and the voltage across each capacitor is VDC. The number of voltage levels in MC can be increased by adding the additional capacitors, diodes and power devices. The clamping diodes are used to limit stress on the power device $[6,7]$. NPC-MC challenges to overcome specific of the weaknesses of cascaded-MCs sorts, such as it does not necessitate separated DC supplies. Although, these types of inverters having some disadvantage or problem like de link unbalance [4].

Generally in MC, phase voltage (i.e. voltage across one leg) of an k-level converter has k levels together with zero reference level, and thus the line voltage level (voltage between two inverter legs) has $\mathrm{k}^{\prime}$ level, is equal to $2 \mathrm{k}-1$ levels, so the output voltage of seven (line) level, has four (phase leg) level [6].

The component requirement for this type of converters as following: Number of DC link capacitor $=\mathrm{k}-1$, number of clamping diodes for each phase leg $=(\mathrm{k}-1) *(\mathrm{k}-2)$, and number of main power switches for each phase leg of converter $=2 \mathrm{k}-2$. So, for seven level ( 4 phase level) NPC-MC, thee DC bus capacitors are used $(\mathrm{C} 1, \mathrm{C} 2$, and $\mathrm{C} 3)$ as shown in Figure 1 (a). Ideally voltage across each capacitor should be third of the amplitude of the DC Supply (VDC/3), and therefore, the voltage stress of every device will be decreased to one capacitor voltage level VDC/3 through clamping diodes. Moreover, six power switches and six of power switch and six of clamping diodes are used for each phase leg.

\section{SEVEN LEVEL CASCADED MULTILEVEL CONVERTER}

The cascaded-MC is one of the standard converter types used for high power applications. Compared to other types of MCs, this type requires smallest amount of components for same voltage level without further clamping diodes or voltage balancing capacitors. The modularity property (i.e. simpler modular arrangement) of these types of converters allows to practically building high number of levels for the cascaded-MCs by assembling the units with ease packaging. The working of the cascaded-MC can be simply comprehended. The output voltage is equivalent to the accumulation of the output voltage of the individual units that are coupled in series. The No. of $\mathrm{H}$-bridge modules $(\mathrm{H})$ which is equivalent to the No. of DC supply depends on the whole No. of positive, negative and reference levels $\left(k^{\prime}\right)$ of the cascaded-MC. The following equation gives the relation between $H$ and $k^{\prime}$ is [8-10].

$$
H=\left(k^{\prime}-1\right) / 2
$$

Number of main power switches for cascaded-MC $=2 k^{\prime}-2$.So for implementation seven level cascaded-MC, three of H-bridge (which equal to the number of DC source), and twelve of power switches are required. One disadvantage of these types of converters, its needs separate DC power sources there by limiting its utility and applications. A seven level cascaded-MC comprises of 3 cascade H-bridges as displayed in Figure 1(b). 


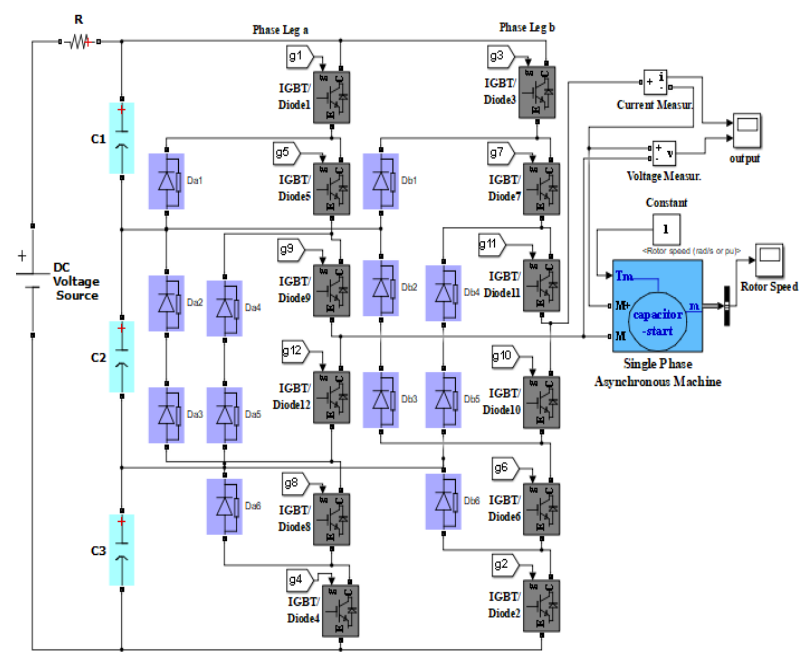

(a)

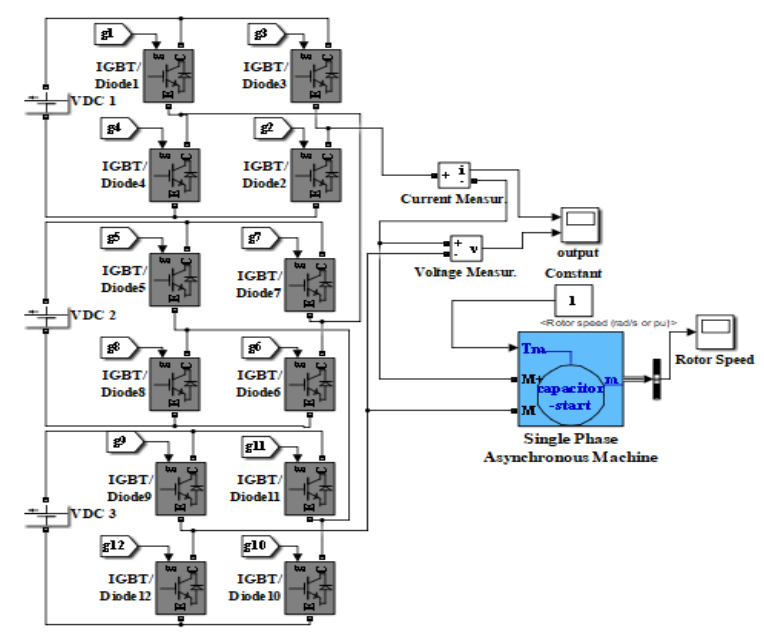

(b)

Figure 1. Block diagram of simulation of seven level converter: (a) NPC-MC, (b) Cascaded-MC

\section{SINGLE PHASE CAPACITOR-START MOTOR:}

Single-phase induction motors are typically two-pole or four-pole, rated at $2 \mathrm{hp}$ or less, while slower and greater motor can be manufactured for special uses [11]. The work is carried out on $1 \mathrm{HP}, 220 \mathrm{~V}, 50 \mathrm{~Hz}$ single phase capacitor start motor as load for the seven level inverter at all circuit configurations, the motor has the parameter listed in Table 1.

Table 1. Motor specifications

\begin{tabular}{lr}
\hline \multicolumn{1}{c}{ Parameter } & Value \\
\hline Main winding stator resistance $\left(R_{s m}\right)$ & $4 \Omega$ \\
Main winding stator leakage inductance $\left(L_{s m}\right)$ & $0.0203 \mathrm{H}$ \\
Auxiliary winding stator resistance $\left(R_{s a}\right)$ & $6.5 \Omega$ \\
Auxiliary winding stator leakage inductance $\left(L_{s a}\right)$ & $0.021 \mathrm{H}$ \\
Main winding rotor resistance $\left(R_{r m}^{\prime}\right)$ & $3.61 \Omega$ \\
Main winding rotor leakage inductance $\left(L_{r m}^{\prime}\right)$ & $0.0304 \mathrm{H}$ \\
Main winding mutual inductance $\left(L_{m}\right)$ & $0.1954 \mathrm{H}$ \\
Combined rotor and load inertia coefficient $(J)$ & $0.01424 \mathrm{Kg} . \mathrm{m}^{2}$ \\
Capacitor-Start $(\mathrm{C})$ & $40 \mu \mathrm{F}$ \\
\hline
\end{tabular}

Int J Pow Elec \& Dri Syst, Vol. 10, No. 2, June 2019: $662-671$ 


\subsection{Multicarrier modulation techniques}

Modulation technique used for MCs can be classified into two categories: Low Switching Frequency (LSF) as selective harmonic elimination method which operated at switching frequency equal to a frequency of output voltage, and High Switching Frequency (HSF) for high switching frequency is considered above $1 \mathrm{KHz}$ as Space vector method and Multicarrier modulation techniques. In selective harmonic elimination method is required additional precise iterative process through solving its nonlinear equation to produce optimal switching angle. In which the Space vector method is more complex and it needs further calculations, further is difficulty to be extended when the level of the converter changes [5].

The Multicarrier techniques are the popular method used for MCs can be commonly categorized into two groups: Phase Shifted Carrier (PSC) and Level Shifted Carrier (LSC) modulation techniques. Both modulation techniques are applied for cascaded and FLC converters, where only the LSC modulation techniques are applied for NPC converter.

\subsubsection{Phase shifted carrier modulation technique}

Generally, a MC with $k^{\prime}$ voltage levels needs $k^{\prime}-1$ triangular carriers with the identical frequency and the identical peak-to-peak amplitude, but there is a phase shift $\varphi_{c r}$ equal to $360^{\circ} /\left(k^{\prime}-1\right)$ between every two adjacent carrier waves, given by Thus for seven level multilevel inverter six carrier waves are required $\left(\mathrm{V}_{\mathrm{cr} 1}, \mathrm{~V}_{\mathrm{cr} 2}, \mathrm{~V}_{\mathrm{cr} 3}, \mathrm{~V}_{\mathrm{cr} 1-}, \mathrm{V}_{\mathrm{cr} 2-}, \mathrm{V}_{\mathrm{cr} 3-}\right)$ with a $60^{\circ}$ phase displacements between any two adjacent carriers as presented in Figure2 (a). The reference waveform $\mathrm{V}_{\mathrm{mA}}$ is placed at zero reference and always compared with each of the carrier waves. If the reference wave is greater than a carrier signal, then the active switches corresponding to that carrier are turned ON. Else, the power switch is switched OFF $[8,12]$.

Simulation of PSC modulation techniques for seven level converter carried out using Matlab /Simulink software is depicted in Figure2 (b). Six carrier waves are required thus one carrier wave used and then shifted five times by using Transport Delay Block. Switching frequency of the carrier wave is set to 950 $\mathrm{Hz}$, and $1 \mathrm{KHz}$.

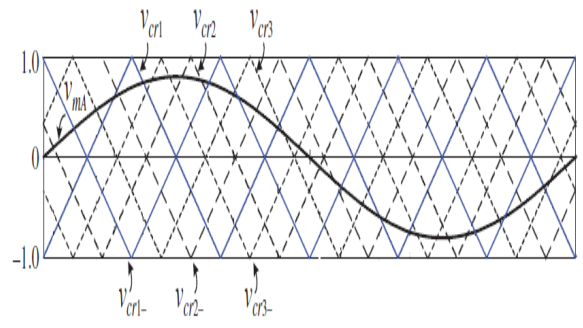

(a)

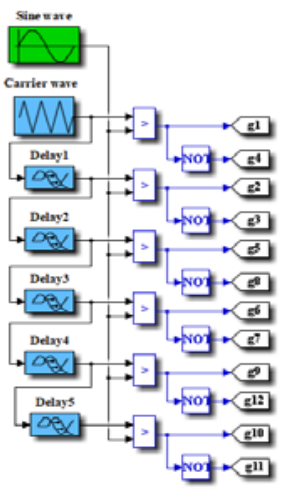

(b)

Figure 2. PSC modulation technique. (a) Principle operation of the technique,

(b) Simulation block diagram

\subsubsection{Level shifted carrier modulation technique}

As in previous technique for $k^{\prime}$ level inverter, $k^{\prime}-1$ carrier waves with the same frequency and amplitude are required. But here these carrier waves are vertically disposed such that the bands they occupy are contiguous instead of horizontally disposed as in phase shifted technique. This mode has three types according to the arrangement of carrier waves [9]:

a) With phase array (In-phase Disposition IPD)

In this type, all the carrier waves are the same phase as shown in Figure3 (a).

b) Phase Opposition Disposition POD

This technique is also named as "Anti-phase arrangement" because each of the positive carriers (carrier waves above zero reference) are in phase, but with a phase shift of $180^{\circ}$ regarding to the negative carriers (carrier waves below zero reference) as show in Figure3 (b).

c) Alternative Phase Opposition Disposition APOD 
This technique is also called as "Alternately reverse phase array" since each carrier has a phase shift of $180^{\circ}$ from the adjacent carriers as presented in Figure 3 (c).

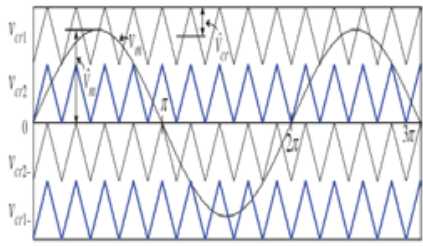

(a)

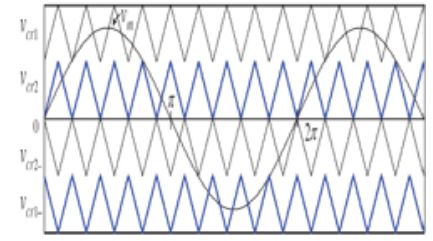

(b)

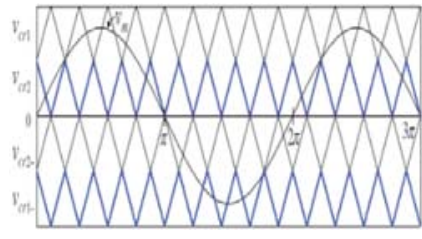

(c)

Figure 3. LSC modulation techniques

For PSC modulation techniques, the amplitude of modulation index $m_{a}$ is given by

$$
\mathrm{m}_{\mathrm{a}}=\frac{\widehat{\mathrm{v}}_{\mathrm{m}}}{\widehat{\mathrm{v}}_{\mathrm{cr}}} \quad 0 \leq \mathrm{m}_{\mathrm{a}} \leq 1
$$

Where $\widehat{V}_{m}$ is the greatest amplitude of reference signal $V_{m}$, and $\widehat{V}_{c r}$ is the greatest amplitude of each carrier signal. In LSC modulation technique, the amplitude of modulation index is differs from PSC and can be defined as:

$$
m_{a}=\frac{\widehat{V}_{m}}{\widehat{V}_{c r *}(k-1)} \quad 0 \leq m_{a} \leq 1
$$

The amplitude of the frequency modulation expression $\left(m_{f}\right)$ can be expressed as:

$$
\mathrm{m}_{\mathrm{f}}=\frac{\mathrm{f}_{\mathrm{cr}}}{\mathrm{f}_{\mathrm{m}}}
$$

where $f_{c r}$, and $f_{m}$ are the frequency amplitude of carrier and modulation signal respectively [8].

Simulation of LSC modulation techniques for seven level converter is depicted in Figure4. Six carrier waves are required to generate twelve gating signals.

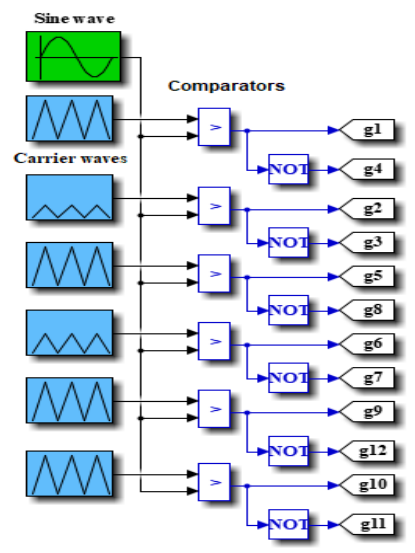

Figure 4. Simulation diagram of IPD-LSC, POD-LSC, APOD-LSC modulation techniques

Percentage of the THD which is a degree of closeness in outline between a waveform and its fundamental component, is used as a performance factor for comparison study in this work. for a voltage signal, the THD can be defined as $[8,9]$ :

Int J Pow Elec \& Dri Syst, Vol. 10, No. 2, June 2019: $662-671$ 


$$
T H D=\frac{\sqrt{\sum_{h=2}^{\max h} V_{h}^{2}}}{V_{1}}
$$

where $V_{h}$ is the rms of harmonic which has order h, and $V_{l}$ is the rms value of the fundamental component.

\section{SIMULATION RESULTS}

The symmetry of the output voltage waveforms of multilevel and its harmonic content are reliant on $m_{f}$ whether if it is odd or even. Therefor in this study, the effects of different $m_{f}$ values on the output voltage waveform and harmonic contents have been investigated for the LSC and PSC modulating techniques.

In order to clarify the and recognizing the type of the symmetry of the output voltage of MC and its effecting on the spectra analysis, Figure 5 to Figure8 show the output voltage waveform of the seven level cascaded converter with different types of modulation techniques. Figure9 to Figure 12 show the load current with corresponding the harmonic spectrum analysis. The converter operated with switching frequency equal to $950 \mathrm{~Hz}$ (i.e. odd $m_{f}=19$ ) first time then with switching frequency equal to $1000 \mathrm{~Hz}$ (i.e. even $m_{f}=20$ ).

Due to limited space, this paper gives seven level cascaded simulation waveform, the remaining simulation results of NPC-MC is nearly the similar as cascaded simulation results.

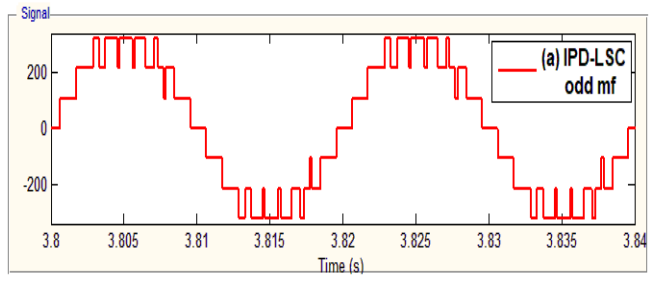

(a)

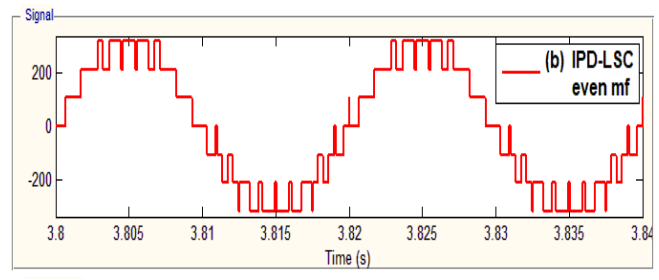

(b)

Figure 5. The cascaded-MC output voltage using IPD-LSC method with its corresponding frequency spectrum: (a) odd $m_{f}$, (b) even $m_{f}$

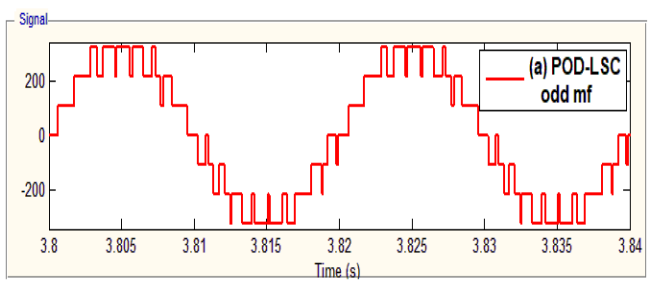

(a)

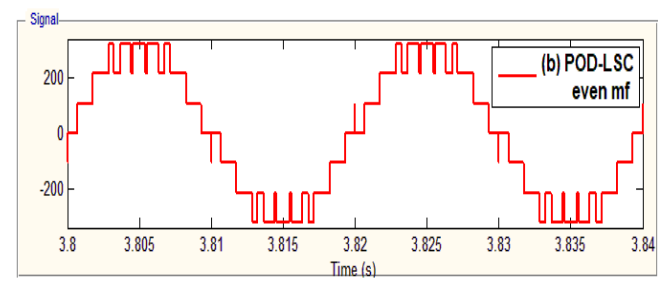

(b)

Figure 6. The cascaded-MC output voltage using POD-LSC method with its corresponding frequency spectrum: (a) odd $m_{f}$, (b) even $m_{f}$

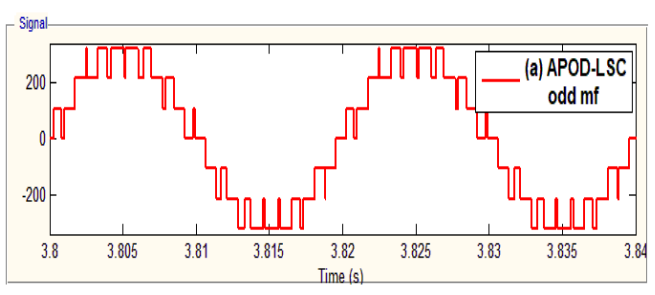

(a)

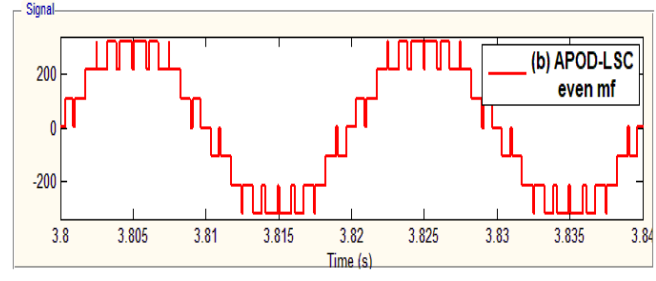

(b)

Figure 7. The cascaded-MC output voltage using APOD-LSC method with its corresponding frequency spectrum: (a) odd $m_{f}$, (b) even $m_{f}$ 


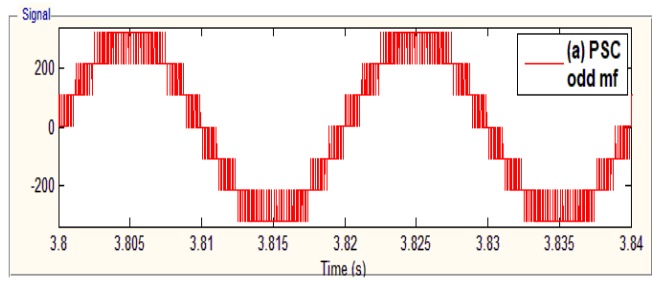

(a)

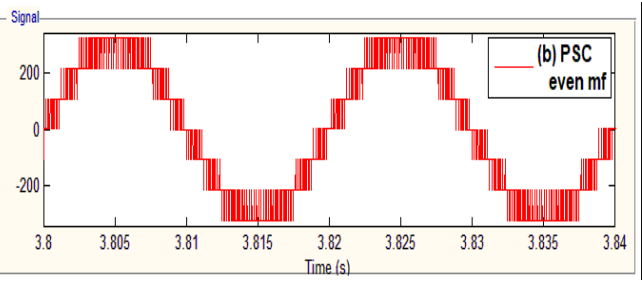

(b)

Figure 8. The cascaded-MC output voltage using PSC method with its corresponding frequency spectrum: (a) odd $m_{f}$, (b) even $m_{f}$

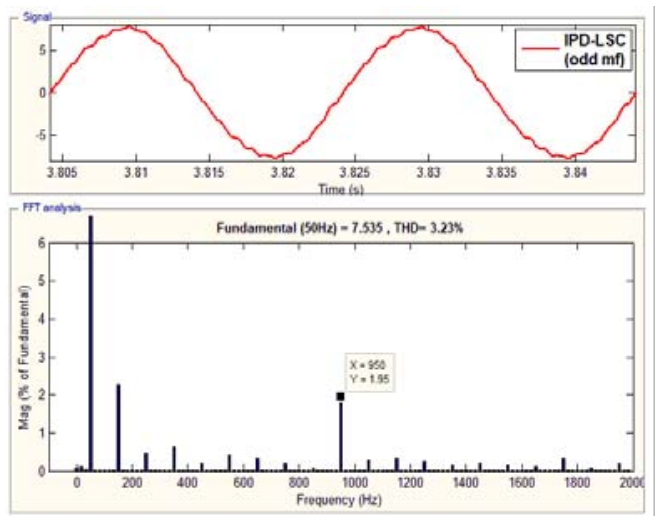

(a)

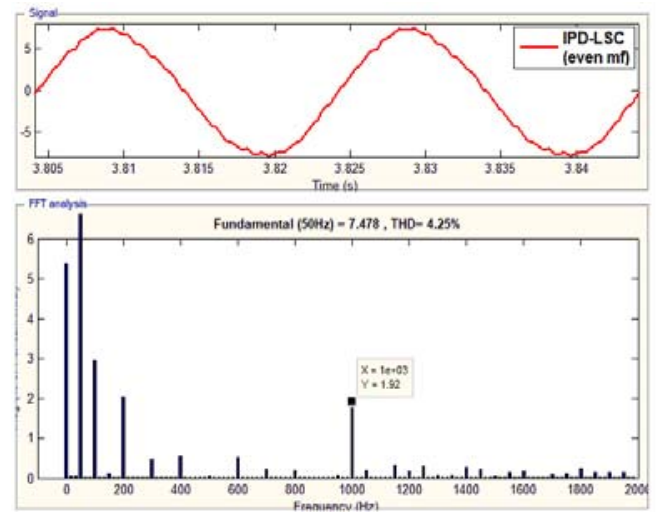

(b)

Figure 9. The cascaded-MC load current using IPD-LSC method with its corresponding frequency spectrum: (a) odd $m_{f}$, (b) even $m_{f}$

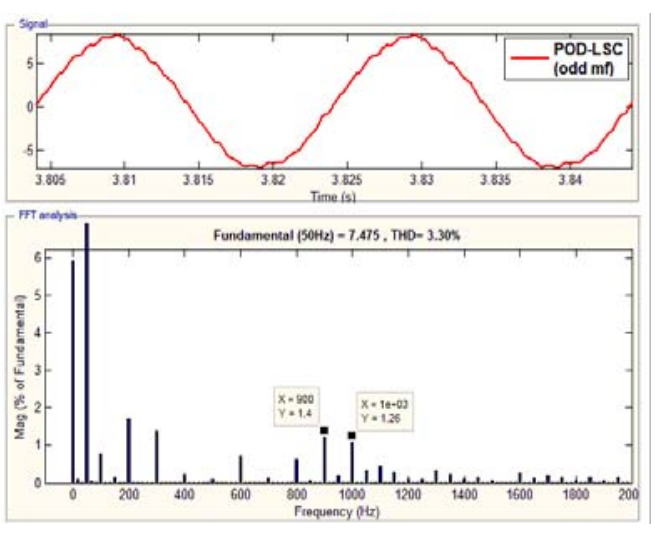

(a)
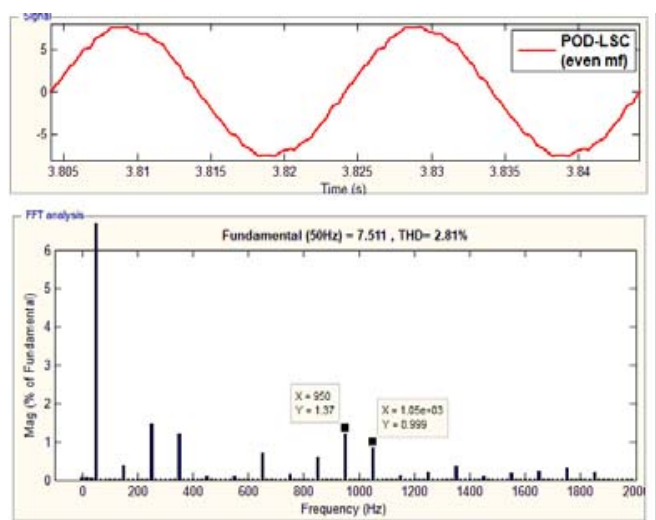

(b)

Figure 10. The cascaded-MC load current using POD-LSC method with its corresponding frequency spectrum: (a) odd $m_{f}$, (b) even $m_{f}$ 


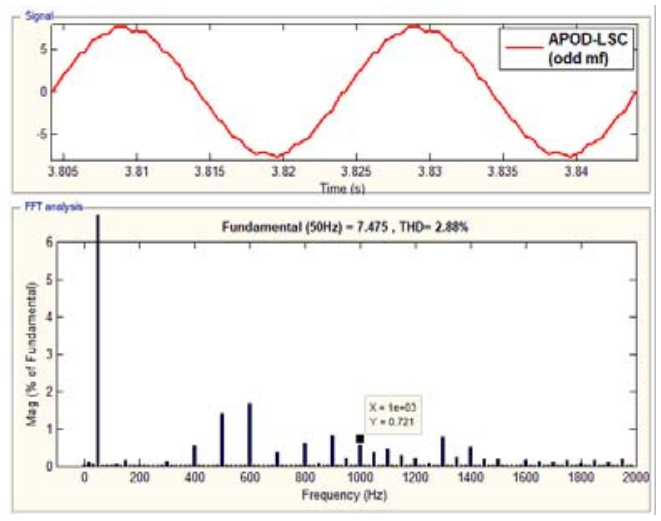

(a)

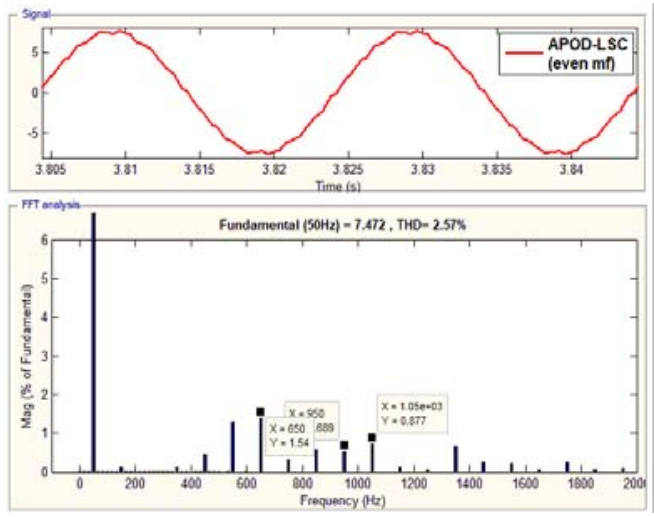

(b)

Figure 11. The cascaded-MC load current using APOD-LSC method with its corresponding frequency spectrum: (a) odd $m_{f}$, (b) even $m_{f}$

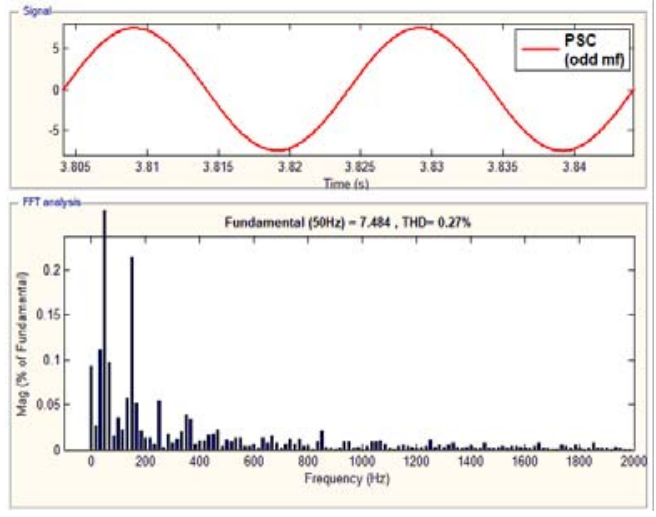

(a)

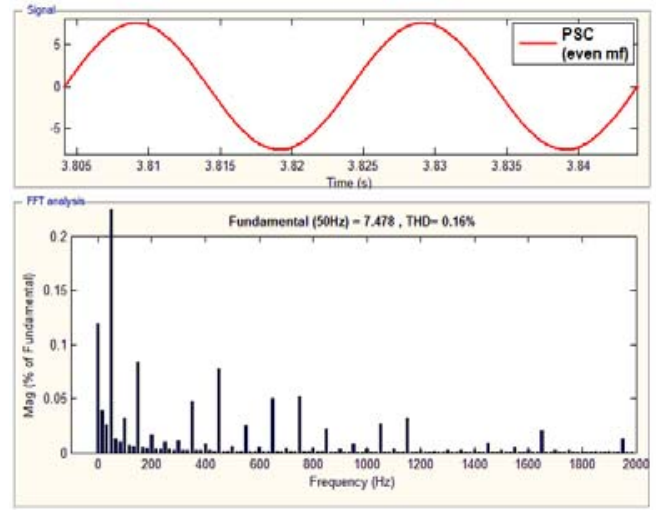

(b)

Figure 12. The cascaded-MC load current using PSC method with its corresponding frequency spectrum: (a) odd $m_{f}$, (b) even $m_{f}$

It observed the following:

1- In IPD-LSC modulation technique, the output voltage waveform is half wave symmetry for odd $m_{f}$ and odd symmetry for even $m_{f}$, thus only odd harmonics are appear in the harmonics spectra at odd $m_{f}$ while even plus odd harmonics are appear at operating on even $m_{f}$, thus its prefer to operate the converter at odd $m_{f}$ when using this technique. The significant harmonic energy in this technique is focus at the carrier frequency $(950 \mathrm{~Hz}, 1000 \mathrm{~Hz})$.

2- In POD-LSC modulation technique, the most significant harmonics are found in two sidebands nearby the carrier frequency as shown in the harmonic spectra with no harmonic appear at multiple carrier frequency. For instance, at $f_{c r}=950$ the significant harmonics $18^{\text {th }}$ and $20^{\text {th }}$ harmonics.

3- In APOD-LSC modulation technique, the output voltage waveform has only odd symmetry for odd $m_{f}$ and has odd quarter-wave symmetry for even $m_{f}$. Thus only odd harmonics are appears in the frequency spectrum when the $m_{f}$ is even, while odd plus even harmonics are appear for odd $m_{f}$ in addition to the THD amplitude became higher; so, the $m_{f}$ value in this technique should always be even to obtain best output voltage quality. The main harmonics occur at the sideband. Comparing the above three techniques, the APOD-LSC method has better output voltage quality.

4- In PSC output voltage waveform has odd quarter-wave symmetric for both odd and even $m_{f}$.

In seven level MCs when employing LSC modulation techniques, if the $m_{a}$ decreases down to 0.666 the number of level will decrease also to five and so on for $m_{a}$ lower than 0.333 the number of level will three. Figure 13 shows the effect of variation of amplitude of $m_{a}$ on the number of levels of the output voltage of the MCs with APOD-LSC modulation technique. At beginning the $m_{a}$ equal to 0.9 thus seven output 
voltage will produced, then from 0.04 to $0.08 \mathrm{sec}$ the $m_{a}$ equal to 0.6 thus five level output voltage is generated, finally from 0.08 to $0.12 \mathrm{sec}, m_{a}$ equal to 0.3 , three level voltage is appear at the output.

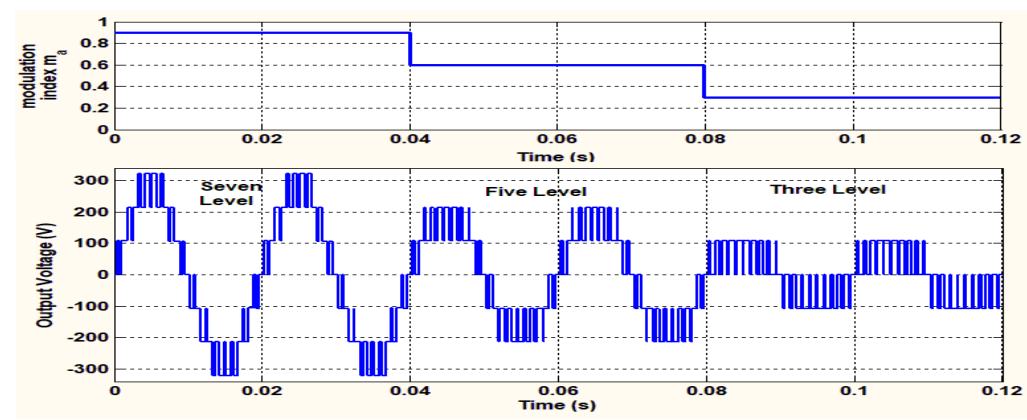

Figure 13. Effect of modulation index on the number of levels of the output voltage of MC

In this study, we investigated the effects of different $m_{f}$ and $m_{a}$ values on the harmonics content and the Vrms of seven level cascaded and NPC-MC for different types of modulation techniques which is given in table 2, and table 3 .

Table 2. Variation of $\mathrm{THD}_{\mathrm{v}}$, and $\mathrm{THD}_{\mathrm{i}}$ belong to variant the $m_{f}$ and $m_{a}$ values for different

\begin{tabular}{|c|c|c|c|c|c|c|c|c|c|c|}
\hline \multirow[t]{3}{*}{ Types of converter } & \multirow{3}{*}{$\begin{array}{c}\text { Frequency } \\
\text { modulation } \\
\text { index }\left(m_{f}\right)\end{array}$} & \multirow{3}{*}{$\begin{array}{c}\text { Modulation } \\
\text { index }\left(m_{a}\right)\end{array}$} & \multicolumn{6}{|c|}{ LSC } & \multicolumn{2}{|c|}{ PSC } \\
\hline & & & \multicolumn{2}{|c|}{ IPD } & \multicolumn{2}{|c|}{ POD } & \multicolumn{2}{|c|}{ APOD } & \\
\hline & & & $\mathrm{HD}_{\mathrm{v}}$ & $\mathrm{HD}_{\mathrm{i}}$ & $\mathrm{HD}_{\mathrm{v}}$ & $\mathrm{HD}_{\mathrm{i}}$ & $\mathrm{HD}_{\mathrm{v}}$ & $\mathrm{HD}_{\mathrm{i}}$ & $\mathrm{HD}_{\mathrm{v}}$ & $\mathrm{HD}_{\mathrm{i}}$ \\
\hline \multirow[t]{6}{*}{ Cascaded-MC } & \multirow[t]{3}{*}{19} & 0.6 & 8.86 & 0.01 & 8.30 & 9.45 & 28.27 & 9.02 & .75 & .95 \\
\hline & & 0.8 & 0.60 & .56 & 0.48 & 9.87 & 0.64 & 8.77 & .51 & .15 \\
\hline & & 1 & 3.81 & .78 & 4.89 & .46 & 5.02 & .73 & .44 & .3 \\
\hline & \multirow[t]{3}{*}{20} & 0.6 & 8 & 9.41 & 7.14 & 7.70 & 8.42 & 7.49 & .94 & .45 \\
\hline & & 0.8 & 0.36 & 0 & 0.10 & 7.55 & 2.26 & 7.98 & .59 & .39 \\
\hline & & 1 & 4.66 & .26 & 3.75 & .90 & 3.45 & .43 & .45 & .21 \\
\hline \multirow[t]{6}{*}{ NPC-MC } & \multirow[t]{3}{*}{19} & 0.6 & 8.95 & 9.93 & 8.35 & 9.42 & 8.30 & 8.91 & .75 & .88 \\
\hline & & 0.8 & 0.64 & 0.92 & 0.50 & 0.34 & 0.64 & 9.07 & .56 & .16 \\
\hline & & 1 & 3.79 & .72 & 4.93 & .38 & 5.08 & .73 & .46 & .27 \\
\hline & \multirow[t]{3}{*}{20} & 0.6 & 7.99 & 9.42 & 7.13 & 7.62 & 8.41 & 7.44 & .95 & .41 \\
\hline & & 0.8 & 0.37 & 0.59 & 0.11 & 8.13 & 2.26 & 8.66 & .60 & .17 \\
\hline & & 1 & 4.67 & .26 & 3.76 & .90 & 3.45 & .43 & .47 & .22 \\
\hline
\end{tabular}

It is observed that the best THD values are obtained at $m_{a}=1$, and when its decrease, a great negative affects occurred on the harmonics content of the waveform of the MCs especially when employed LSC technique because the number of the output voltage level will decrease also.

Table 3. Variation of Vrms belong to variant the $m_{a}$ values for different modulation techniques

\begin{tabular}{cccccc}
\hline Types of converter & $\begin{array}{c}\text { Modulation } \\
\text { index }\left(m_{a}\right)\end{array}$ & $\begin{array}{c}\text { IPD } \\
\text { Vrms }(V)\end{array}$ & $\begin{array}{c}\text { LSC } \\
\text { Prms }(V)\end{array}$ & $\begin{array}{c}\text { APOD } \\
\text { Vrms }(V)\end{array}$ & Vrms $(V)$ \\
\hline Cascaded-MC & 0.6 & 135.9 & 136.3 & 136.3 & 136.2 \\
& 0.8 & 182.1 & 181.6 & 181.6 & 181.5 \\
NPC-MC & 1 & 228.6 & 227 & 227 & 226.8 \\
& 0.6 & 133.1 & 133.5 & 133.5 & 133.6 \\
& 0.8 & 178.6 & 178.1 & 178.1 & 1777.9 \\
& 1 & 224.3 & 222.5 & 222.5 & 222.5 \\
\hline
\end{tabular}

It is seen that the DC-bus utilization in cascaded-MC is greater than in case of using NPC-MC for motor drive.

Int J Pow Elec \& Dri Syst, Vol. 10, No. 2, June 2019: $662-671$ 


\section{CONCLUSION}

Generally, the cascaded-MC has superior advantage over other types, as it required lower amount of component in addition to it has less harmonic content in the output voltage waveform. The harmonics contents of the output voltage of the MC can be reduced by employing multicarrier modulation techniques. The PSC modulation technique is the best method compared with the other as it is offer output with very low THD amplitude. It is observed the amplitude of the THD values of POD and APOD schemes are lower at $m_{f}$ is even (at $f_{c r}=1000$ ) compared to the THD values at the $m_{f}$ is odd (at $f_{c r}=950$ ). It is seen the APOD-LSC modulation technique is found to perform better compared with the other LSC techniques as it has odd quarter wave symmetry, thus it provides relatively low THD value.

\section{REFERENCES}

[1] Khoukha Imarazene, El M. Berkouk, Hachemi Chekireb, "New dc-link balancing algorithm for multilevel inverter in photovoltaic system", IEEE International Conference on Industrial Technology, Toronto, Canada, 2017, pp. 159-164.

[2] N. Susheel, Kumar P. Satish, "Performance analysis of FPGA based diode clamped multilevel inverter fed induction motor drive using phase opposition disposition multicarrier based modulation Strategy", International Journal of Power Electronics and Drive System (IJPEDS), vol. 8, no. 4, pp. 1512-1523, 2017.

[3] Kelam B. M. Reddy, Swapnajit Pattnaik, "Novel symmetric and asymmetric topology of multilevel inverter with reduced number of switches", IEEE International Conference on Industrial Technology, Toronto, Canada, 2017, pp. $165-170$

[4] M. E. Kathar, S. M. Kulkarni, "Comparative study of multilevel inverter topologies", International Journal of Engineering Sciences \& Research Technologyz, vol. 6, no. 4, pp. 221-224, 2017.

[5] S. Usha, C. Subramani, A. Geetha, "Performance Analysis of H-bridge and T-Bridge Multilevel Inverters for Harmonics Reduction", International Journal of Power Electronics and Drive System (IJPEDS), vol. 9, no. 1, pp. 231-239, 2018.

[6] M.Madhu Shobini, J. Kamala, R.Rathna, "Analysis and simulation of flying capacitor multilevel inverter using PDPWM strategy", International IEEE Conference on Innovative Mechanisms for Industry Applications, India, pp. 91-95, 2017.

[7] Sourabh Kundu, Santu Kr. Giri, Sarbani Mukherjee, Subrata Banerjee, "Performance analysis of three-phase fivelevel NPC inverter by using triangular and trapezoidal triangular carrier-based modulation techniques", $4^{\text {th }}$ IEEE International Conference on Power, Control \& Embedded Systems, Allahabad, India, pp. 1-6, 2017.

[8] Pegah Hamedani, Abbas Shoulaie, "A comparative study of harmonic distortion in multicarrier based PWM switching techniques for cascaded H-bridge inverters", Advances in Electrical and Computer Engineering, vol. 16, no. 3, pp. 15-24, 2016.

[9] B. V. L. Kala Bharathi, V. Srinivasa Rao, "Comparative analysis of multi carrier PWM eleven level inverter with two modulation waves", IEEE International Conference on Power, Control, Signals and Instrumentation Engineering, India, 2017, pp. 2564-2572.

[10] Hashim Hasabelrasul, Xiangwu Yan, "Comparison of Multicarrier PWM Techniques for Cascaded H-Bridge Multilevel Inverter", International Journal of Power Electronics and Drive System (IJPEDS), vol. 8, no. 2, pp. 861-868, 2017.

[11] Mahmoud M. Elkholy, "Optimal energy saving for variable speed single phase induction motor drives", $19^{\text {th }}$ IEEE International Middle East Power Systems Conference, Cairo, Egypt, 2017. pp. 753 - 764.

[12] Bin Wu, and Mehdi Narimani, "High power converters and AC drives", Second Edition, Published 2017 by John Wiley \& Sons, Inc. 